\title{
COCRIAÇÃO E GESTÃO DO DESIGN EM PEQUENAS EMPRESAS RURAIS E PESQUEIRAS: UMA ABORDAGEM SUSTENTÁVEL.
}

\section{CO-CREATION AND DESIGN MANAGEMENT IN SMALL RURAL FISHING ENTERPRISES: A SUSTAINABLE APPROACH}

\author{
Giancarlo Philippi Zacchi, doutorando em Design (UFSC); \\ Eugênio Andrés Díaz Merino, Dr. (UFSC); \\ Giselle Schmidt Alves Díaz Merino, Dra (UFSC).
}

\author{
Palavras Chave \\ Gestão de design; Cocriação; Sustentabilidade.
}

\author{
Key Words \\ Design management; Co-creation; Sustainability.
}

\section{RESUMO}

A agricultura familiar apresenta-se pujante nas últimas décadas e seu desenvolvimento aponta para outros desafios nas questões ambientais e de relacionamento com o mercado. Contudo, mesmo diante de tantas facilidades tecnológicas, econômicas e políticas, essas empresas encontram dificuldade para comercializar seus produtos. Neste panorama a gestão de design se defronta em um contexto para propor soluções a esses desafios, por meio de processos de cocriação. O objetivo é identificar por meio da gestão de design, formas de se agir intencionalmente com a abordagem da cocriação para promoção da sustentabilidade, mais ao mesmo tempo preocupa-se com a identificação da produção de seus aspectos e impactos ambientais. Este artigo caracteriza-se como uma pesquisa de natureza aplicada, com objetivo exploratório, abordagem qualitativa, com procedimento metodológico documental e bibliográfico. Como resultados aponta-se que a cocriação até o presente momento, para os casos estudados, trouxe benefícios; que na agricultura familiar a abordagem deve levar em conta aspectos fitossanitários, climáticos e sazonais e que estudos devem ser estimulados, com a finalidade de ampliar este escopo teórico para que essa abordagem, mediada pela prática da gestão de design contribua para o desenvolvimento sustentável na práxis produtiva e gerencial e que a abertura de um canal de comunicação entre os clientes e mais de um produtor rural, aplicando um ou mais modelos apresentados neste artigo, por exemplo, deve ser aplicado para que avaliações comparativas possam ser efetuadas e hipóteses levantadas, confirmadas ou não.

\section{ABSTRACT :}

Family farming has grown stronger in recent decades and its development aims for further challenges regarding environmental issues and relationship with the market. However, even in face of many technological facilities and economic and political resources, these companies have difficulties in marketing their products. In this scenario the design management copes with a context to propose solutions for these challenges through co-creation processes. The purpose is to identify through design management, ways of acting intentionally with co-creation approach to promote sustainability, but at the same time it is concerned with identifying its production and environmental impacts. This article is characterized by applied research, with exploratory objective, qualitative approach, with a methodological,documental and bibliographic procedure. As a result, it is pointed that co-creation has brought benefits to the case studies, that in family farming its approach should take phytosanitary, climatic and seasonal aspects into account but also studies should be encouraged in order to extend the theoreticalscope for this approach, mediated by the practice of design management to contribute towards a sustainable development in production and management praxis and that the opening of a communication channel between customers and more than one farmer, applying one or more models presented in this study, should be applied to ensure that benchmarking can be set and hypotheses raised, confirmed or not. 


\section{INTRODUÇÃO}

A agricultura familiar tem sido alvo constante de políticas públicas e nos últimos anos renasce fortalecida, diversificada e sustentável. Essas políticas que chegam ao rural brasileiro oferecem aos agricultores e agricultoras mais respeito, segurança e autonomia, desempenhando papel fundamental na estratégia de superação da fome e da promoção de alimentos seguros (BRASIL, 2016).

Para Sabourim, Samper e Massardier (2015, p.598), essas políticas reúnem instrumentos diferentes num mesmo marco de política nacional e afirmam isso comparando o Indap no Chile, o Pronaf no Brasil, o Proinder na Argentina e o Crissol na Nicarágua referindo-se que o modelo "faz do apoio específico à categoria da agricultura familiar um objetivo em si mesmo", uma vez que comporta um perímetro de intervenção com dispositivos de prestação de serviços de crédito, capacitação, assistência técnica e projetos participativos.

Muito embora o setor possa apresentar características específicas que a tornam diferenciada de outros segmentos do agronegócio, é necessária uma lógica sistêmica de integração com o mercado, visto que, segundo OCED/ FAO (2015) o crescimento agrícola no Brasil tem gerado impacto significativo no acesso ao abastecimento de alimentos no mercado interno.

Para Conceição (2015) o Programa de Aquisição de Alimentos (PPA) e o Programa de Garantia de Preços para a Agricultura Familiar (PGPAF) mostram-se como uma nova alteração na política de comercialização agrícola. Contudo, segundo Chmielewska, Souza e Lourete (2010) o programa tem gerado impactos expressivos na redução da pobreza e na segurança alimentar apesar das críticas e desafios.

Além disso, o processo de desenvolvimento econômico, resultante do avanço tecnológico estabelece uma sucessão de desafios. Esses fatores externos criam novos caminhos e agendas, tal como a discussão sobre o aquecimento global e seus impactos além de boas soluções logísticas antes e depois da porteira (BARROS, 2014).

A agricultura familiar é o modo agrícola predominante do mundo, responsável por $80 \%$ da produção de alimentos no planeta. Também é responsável pela segurança alimentar, bem-estar da comunidade, da economia, da conservação e exploração agrícola mundial, da biodiversidade e do uso sustentável dos recursos naturais, bem como resiliência climática (FAO, 2014).

No entanto mesmo diante de políticas públicas e de ferramentas que auxiliam os pequenos produtores a se tornarem mais competitivos, diferenciados e sustentáveis e o país apresentar expressivo crescimento no comércio internacional consolidando sua posição como um dos maiores produtores e exportadores de alimentos para mais de 200 países, ainda é possível verificar que o cenário econômico internacional segue manifestando-se de forma preocupante (BRASIL, 2016a).

A desaceleração do crescimento em diversos países, a desvalorização das moedas e a volatilidade dos mercados criam dificuldades para recuperação no curto prazo e isso significa que outras cadeias produtivas tenderão a se encurtar (IPEA, 2016).

No que concerne ao ambiente externo, é exigido do pequeno produtor eficiência na área tecnológica e de gestão para que ele possa acompanhar as mudanças que estão ocorrendo no mundo. Além de produzir de forma economicamente viável, socialmente justa e ecologicamente correta também é inerente o desenvolvimento de ações econômicas em redes de relações sociais, vez que essas ligações constitutivas, favorecem a tomada de decisão (FERRARI, et al, 2014).

A gestão de design busca identificar fragilidades e oportunidades para a prática projetual e contribuir com a dinamização competitiva, diferenciada e sustentável da agricultura familiar, como pode ser visto em Teixeira, (2013); Figueiredo, Merino, Muniz e Merino, (2009); Garcia, et al, (2014) e Merino, (2010), entre outros.

Neste contexto a abordagem da cocriação, assume papel relevante para que a gestão de design aperfeiçoe os processos produtivos das pequenas propriedades rurais e pesqueiras, no sentido de obter a participação dos envolvidos na criação de produtos que satisfaçam as necessidades dos clientes, mas que também se preocupem com a dignidade e fragilidade da terra.

O tema cocriação neste contexto tem ocupado as rodas decisórias das pequenas e também das grandes empresas, que buscam, através da integração e discussão, ampliar as perspectivas de agregar valor nos bens e serviços produzidos por elas mesmas. Isso possibilita que pessoas com diversos perfis e diferentes hierarquias, conhecimentos e experiências influenciem e contribuam para o negócio, o tornando mais inovador (SEBRAE, 2015).

As reflexões sustentadas e os resultados apontados na literatura mostram que o tema e sua abordagem podem trazer resultados positivos para o êxito da cocriação de valor na lógica dominante de serviço, destacando-se os estudos de Grillo, et al, (2014).

A concepção gira em torno também da contribuição que a cocriação pode desencadear para o sucesso e atingimento de comportamentos menos agressivos sobre o meio ambiente e que proporcionem no mercado um valor na identidade da marca, a partir de processos produtivos menos agressivos. 
Dessa forma enfatiza-se que o processo de cocriação estimulado por meio da gestão de design evidencia uma cultura de convergência, de sinergia, e do processo participativo apoiado no princípio de que a empresa vende experiência, e não somente produto, através de um processo de engajamento.

Como é sabido que os consumidores conhecem os novos produtos e assim os rejeitam ou os adotam (KOTLER, 1998), fica evidente que a abordagem da cocriação como uma ferramenta da gestão de design, na criação do produto, deve ser uma estratégia adotada pelos pequenos empreendimentos rurais e pesqueiros, para penetrarem em novos mercados, transformando os novos consumidores, em usuários regulares, alimentando a lealdade com a marca, uma vez que marcas fortes são construídas por meio de uma experiência total (MATOS et al., 2014).

Por outro lado encoraja também a adoção de ferramentas que investiguem a produção de aspectos e de impactos ambientais (SEIFERT, 2007) do seu negócio sobre o meio ambiente, modelando processos produtivos menos nocivos e refinando as práticas já desenvolvidas. A confluência desses dois movimentos proporciona entre outras variantes a formação de empresas sustentáveis e estimula o desenvolvimento da temática de design para o comportamento sustentável (MUNIZ; SANTOS, 2015).

Desta forma, este artigo teórico, objetiva identificar por meio da gestão de design, formas de se agir intencionalmente com a abordagem da cocriação para promoção da sustentabilidade (MONTIBELLER FILHO, 2004), mais ao mesmo tempo preocupa-se com a identificação da produção de seus aspectos e impactos ambientais, melhorando, a qualidade de vida das pessoas com quem mantém interação direta e indireta.

Para tanto, este artigo caracteriza-se como uma pesquisa de natureza aplicada, com objetivo exploratório, abordagem qualitativa, com procedimento metodológico documental e bibliográfico, e apresenta como problema a ser respondido como a abordagem da cocriação pode diminuir as distâncias entre a planta organizacional e o cliente e ao mesmo tempo otimizar seu desempenho socioambiental?

\section{A GESTÃO DE DESIGN E A COCRIAÇÃO: DESAFIOS PARA ENFRENTAR E RESOLVER QUESTÕES AMBIENTAIS NAS PEQUENAS EMPRESAS RURAIS E PESQUEIRAS}

O modelo de desenvolvimento econômico das últimas décadas tem gerado no âmbito das relações comerciais, consequências extremadamente graves no âmbito das relações ambientais e isso vêm colocando em cheque a longevidade das empresas em todos os níveis e segmentos, sobretudo no que toca a identidade e a marca, bem como sua reputação patrimonial.

No meio deste comportamento o mercado procura encontrar ferramentas que minimizem a produção de aspectos e impactos ambientais, na medida em que os próprios consumidores se percebem mais críticos e seletivos, exigindo das plantas organizacionais, comportamentos menos agressivos e mais inovadores. Como consequência disso, diversas tentativas de relacionamento envolvendo clientes, fornecedores e infraestrutura são desencadeados através de atividades de marketing a fim de criar uma cadeia de parceiros da empresa (SHETH, PARVATIYAR, 1995).

As bases para essa integração e compartilhamento residem em um relacionamento orientado pelo conceito de cocriação, o que proporciona vantagem competitiva, uma vez o mercado apontar as suas demandas e sugestões, de forma organizada e colaborativa.

Talvez a criação de programas de melhoria de desempenho ambiental seja o elo necessário ou suficiente para que a planta possa desencadear um processo de implantação de uma governança ambiental corporativa, mas o que se postula essencialmente é o desenvolvimento de práticas mais transparentes, formuladas com estratégias que respeitem os direitos humanos, a proteção ambiental e o combate em todos os níveis de corrupção.

Orientadas por essas mudanças comportamentais, as empresas tentam inovar para se manterem fora de problemas. No entanto, buscam soluções paliativas que em muitos casos, mascaram o problema, repercutindo negativamente em suas marcas, pois o "ambiente artificial em que vivemos é fruto de uma cultura que determina um modo de projetar, produzir, distribuir e consumir" (MALAGUTI, 2008, P. 1).

Por um lado as empresas demandam uma análise crítica de seus processos de produção (BARBARÁ, 2006), realinhando-os com indicadores ambientais e sociais para avaliação de desempenho (BANDEIRA, 2007) e por outro lado, requer que os consumidores revejam seu comportamento, sendo mais seletivos e críticos. Trata-se, de um compromisso de mão dupla.

É justamente neste momento que o conceito de cocriação alinha-se ao de sustentabilidade, uma vez que o tema apresenta aderência ao conceito de inovação empresarial, proporcionando mútua interdependência entre os agentes envolvidos.

É necessário um diálogo constante em um processo que todos os interessados passam a definir valores e agregar benefícios ao produto. Trata-se não só da abertura de um canal de comunicação (PRAHALAD e RAMASWAMY 
2004), mas, sobretudo de um modelo de gestão que facilite a difusão do compartilhamento da experiência e do aprendizado, favorecendo uma relação de confiança. $\mathrm{O}$ papel do consumidor sai do final do processo e se insere para as etapas iniciais da operação produtiva.

Esta integração com a comunidade viabilizada com projetos e parcerias, ocorre com a abordagem da cocriação, e os pequenos empreendimentos rurais e pesqueiros, por sua capacidade de movimentação, absorvem vantagem. Esta atuação corporativa e integrada da gestão de design (NETO; TEIXEIRA; MERINO, 2009) favorece os pequenos, estimula o valor da organização, aumenta sua continuidade, facilita o acesso ao capital e a novas tecnologias e acima de tudo, contribui para a longevidade e preservação do planeta.

A gestão de design pode utilizar a abordagem da cocriação não só no processo decisório da formação do produto e da marca, mas, sobretudo em toda cadeia de valor do negócio em seu escopo competitivo (PORTER, 1989).
Essa responsabilidade e o desejo de participar deste processo não é algo novo. Ela surge com o advento de novos produtos ao longo da história e do próprio mercado. Com a chegada do videocassete, do dvd, e de outros equipamentos eletrodomésticos, por exemplo, quando o consumidor passou a decidir o que ver, ouvir e em que momento. Isso reduz o risco, aumenta o ato de consumo e acima de tudo proporciona integração estratégica, mas, sobretudo com a criação na década de 70 do conceito de coprodução (SEBRAE, 2016).

Ou seja, se anteriormente as premissas do negócio residiam na eficiência produtiva, atualmente elas estão muito mais ligadas e valorizadas à visão que a empresa desenvolve em relação à percepção do cliente e do mercado. Isso torna as empresas mais competitivas, aproximando-as de seu mercado alvo, como pode-se perceber nos exemplos expostos a seguir.

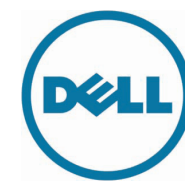

A partir das reclamações de um cliente insatisfeito a empresa desenvolveu um website para receber reclamações e sugestões e hoje estende o espaço como uma sala de estar para receber seus clientes e ouví-los sistematicamente.

Fonte: Jornal do Comércio, 2016

A Starbucks Coffe Company, em período turbulento para o setor cafeeiro, decidiu ouvir seus clientes e isso melhorou seus esforços para estímulo de produção de grãos de alta qualidade, bem como de estratégias sociais de melhoria da condição de vida dos pequenos produtores. Isso a motivou a buscar soluções inovadoras que criassem um sistema cafeeiro mais sustentável econômica, ambiental e socialmente.

Fonte: Austin, Reavis, 2002; Jornal do Comércio, 2016

Desenvolveu uma plataforma de engajamento para o cliente relatar o desempenho de suas corridas e para opinar e sugerir no desenvolvimento de novos produtos. Estimulou o hábito saudável de correr rotineiramente e encorajou seus clientes a arbitrar comentários e sugestões do produto a partir do desempenho individual e do conforto do tênis.

Fonte: Administradores.com, 2016.

A partir de uma contínua análise crítica de seus processos, a empresa passou a questionar como poderia ouvir verdadeiramente seus clientes. A montadora optou pela inovação aberta. A partir de então, a Fiat passou à última etapa, convidando os consumidores a uma nova experiência de integração, fazendo deles verdadeiros produtores de conteúdo, criando um portal.

Fonte: Administradores.com, 2016.

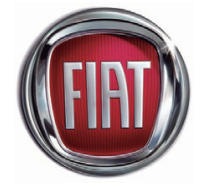




\section{\&3 notura}

A empresa disponibiliza uma plataforma virtual para uma jornada de experiência de cocriação. A empresa estimula o usuário a cadastrar-se no sistema e contribuir para o processo de cocriação, e o usuário ganha pontos por isso. A empresa já finalizou as jornadas viva sua beleza; do meio jeito, cujo problema é como podemos ampliar a sua experiência com cosmético por meio da personalização?; jornada sou e estando no ar a jornada homem, dedicada exclusivamente aos homens da rede.

Fonte: Natura, 2016.

Como é possível perceber com os exemplos acima citados, a estratégia utilizada pelas empresas foi a utilização de plataformas de engajamento, com a finalidade de aproximar o cliente e criar valor à marca. Este método de fora para dentro, estimula um posicionamento de abertura, mas, acima de tudo requer um escopo de liderança que oportunize a tomada de decisão e leve a marca e a vivência da experiência, para dentro da casa do cliente efetivamente, e por sua vez, o mercado para dentro da empresa, como é o caso emblemático a seguir (Figura 1)

Figura 1: Assinatura visual Cirque du Soleil.

\section{CIRQUE DU SOLEIL。}

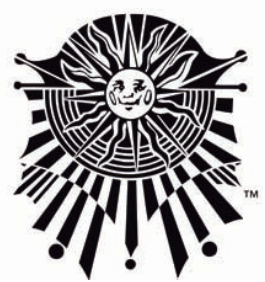

Fonte: Cirque du Soleil 2016.

A ideia de apresentar uma combinação de criação e da dramaturgia, da arquitetura e da arte em geral, levou Guy Laliberté, atual presidente e CEO da companhia artística Circo de Soleil, a encontrar pessoas certas para seu negócio. Essa parceria no modelo de dentro para fora, fez com que o circo contribuísse para o artista crescer, e os artistas fizeram o circo crescer (DELONG, 2006). Eles reúnem recursos e talentos e juntos compõem o que é necessário. Talvez um dos principais resultados desse modelo de cocriação, além da produção de sonho e fantasia, é a perspectiva do estímulo à compreensão da diversidade cultural, pois os artistas da companhia são de diversas partes do mundo.

A companhia criou sites específicos para cada espetáculo, onde os clientes podem expressar suas percepções e vontades e são estimulados a responderem que espetáculos mais gostam estabelecendo uma ordenação por preferência, com a finalidade de que as pessoas criativas do mundo todo busquem o circo e sejam ainda mais criativas, a partir das experiências pessoais, angústias, alegria e imaginação de cada agente cocriativo.
O resultado de toda essa parceria além do sucesso e da frequência de público nos espetáculos é a contribuição que a companhia oferece nas questões urbanas, sociais, ambientais e culturais, com seu estúdio central, em Montreal, cuja finalidade perpassa pelas atribuições administrativas e gerenciais, mas também para o treinamento de seu elenco, em amplos ambientes, dotados de toda segurança, bem como hortas cujo excedente de produção é distribuído entre a população local, mas, sobretudo na intensa e recorrente arte de criar, recriar e reinventar-se ciclicamente.

Diante dos exemplos já citados, entre outros casos, tais como o da indústria de cimento Itambé, do Santander, da Tecnisa, com o estímulo ao consumo colaborativo e o novo conceito de arquitetura inclusiva para a terceira idade, do hospital Moinhos de Vento, no Rio Grande do Sul (WEST; COUTINHO, 2012), da Camiseteria do Rio (JORNAL DO COMÉRCIO, 2010), da Wikipédia (SEBRAE, 2016) e da indústria citrícola paulista (TROCCOLI; ALTAFI, 2012), a abordagem da cocriação torna-se uma vantagem competitiva para as plantas organizacionais.

O processo de cocriação é antes de tudo uma estratégia de interação entre a organização e o cliente, e diante das transformações sistêmicas as corporações tem visto uma mudança no seu papel na sociedade por meio do aumento da complexidade e dinâmica em seus ambientes organizacionais (MISSER, 2013).

Esta relação resulta em um conjunto de ideias que agiliza o processo de inovação e intensifica mudanças no processo de produzir e gerar valor, sendo percebido por todos como uma transformação consequente da interatividade das partes envolvidas.

As pequenas empresas rurais e pesqueiras podem questionar aos consumidores como eles percebem os temas dominantes que se queira discutir estabelecendo a melhor abordagem. Não existem limites para criar. O que existe é saber fazer a pergunta certa na hora certa. Como se pode agregar valor ao negócio? Com quem? O engajamento com os interessados passa a se tornar uma prática em incluir o ponto de vista dos interessados (TAKADA; BELLOTTI, 2013)

A ampliação definitiva da rede de relacionamentos e de parcerias Inter organizacionais é que oportuniza a criação 
de valor (DAFT, 2005). O processo de cocriação resulta desta interatividade: das experiências coletivas e individuais que o mercado passa a estabelecer com as empresas e pela diminuição da inércia, as pequenas, comparativamente às grandes, reúnem muito mais condições nesta esteira.

Portanto um dos mecanismos que as pequenas propriedades rurais e pesqueiras disponibilizam para enfrentar os desafios de serem mais sustentáveis (MERINO, 2008) é perguntar para seu mercado alvo, via de regra e ciclicamente, de que forma ela pode ser sustentável e obter desempenho sustentável.

A simples exposição dessa intenção aumenta a reputação da marca para as questões ambientais. Por outro lado, o próprio cliente passa a se sentir mais valorizado e isso diminui os riscos advindos do produto e dos processos produtivos, uma vez que o principal pilar da cocriação é o desejo latente de colaboração e interação.

Esta relação em rede desenvolve a confiança e o relacionamento passa ser visto como uma relação ganha-ganha, uma vez que o resultado final dessa simbiose é construção de um ativo rentável aumentando o empoderamento de todos os envolvidos.

Assim a gestão de design e a cocriação enfatizam o engajamento das pessoas em diversas etapas do processo, através do estímulo a inteligência criativa, emocional e estratégica (MARQUES, 2007). Rompe com os modelos paradigmáticos imbuídos de criar valor e manobras para satisfação individual dos donos da empresa e seus acionistas, com vistas imediatas do retorno do capital investido, muito embora Pinheiro e Merino (2015, p. 76), apontarem em suas pesquisas que "está cada vez mais claro como gerar ideias novas e úteis, contudo, proporcionalmente pouco se avançou na compreensão objetiva de como extrair valor comercial dessas mesmas ideias." Trata-se de uma nova mentalidade, muito embora sua prática tenha sofrido uma evolução, como se pode constatar com a Figura 2.

Figura 2: Evolução e convergência do processo cocriativo de valor

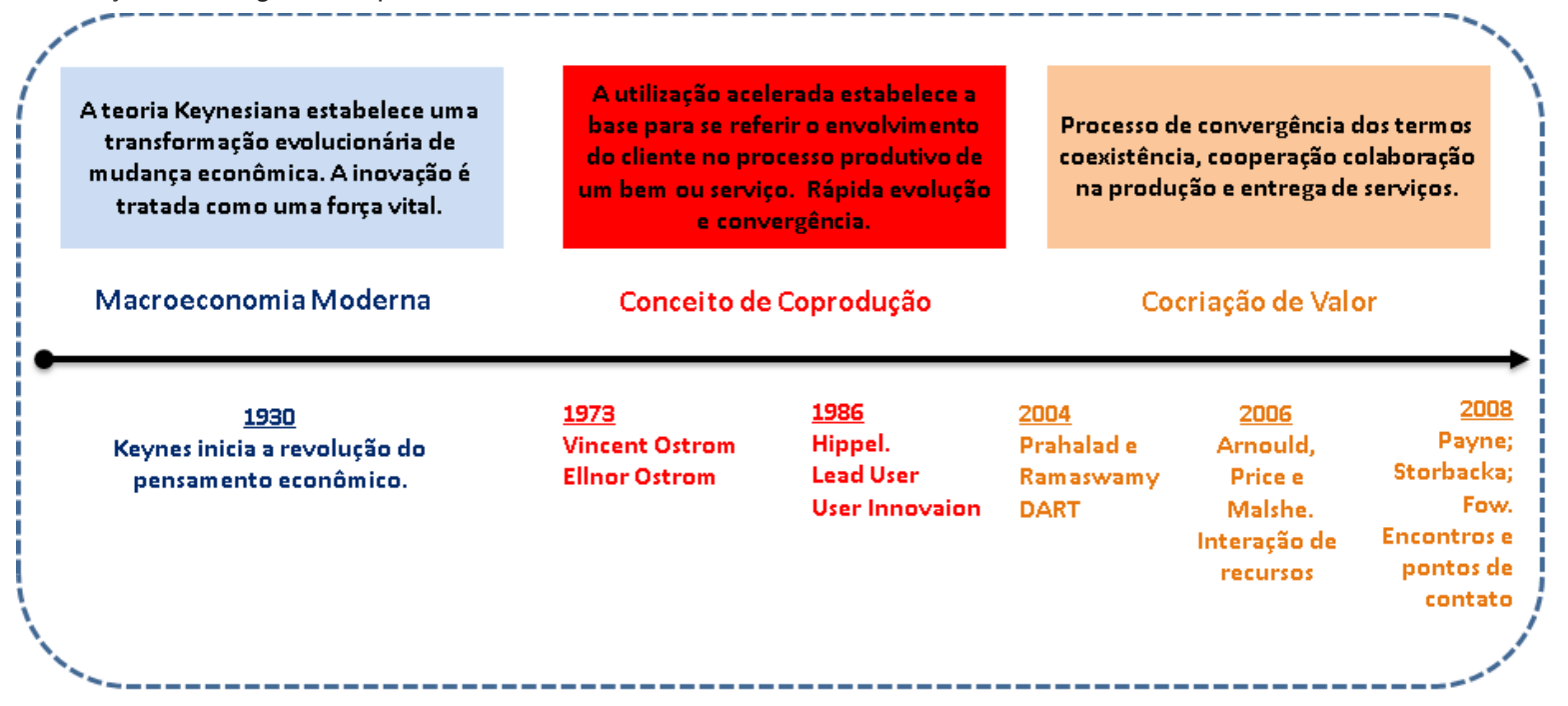

Fonte: Elaborado pelos autores com base em Costa (2013).

A inovação incremental como aumento da eficiência na participação efetiva do mercado e no aperfeiçoamento dos processos produtivos contribuem na formação de indicadores que passam inicialmente a conquista de novos clientes pela inovação, sua fidelização e finalmente captação de valor como margem de produtos oferecidos através de esforços integrados por plataformas de relacionamento e constantes pesquisas. Para Davila, Epstein e Shelton (2007) a proposição de valor agregado ao produto ou serviço é uma condicionante que deve proporcionar evolução no modelo de negócio.

Percebe-se que a convergência dos termos coprodução e cocriação apresentam um contínuo relacional evolutivo, que coloca o cliente e o mercado na ponta do processo de produção, em um mecanismo cíclico aumentando a cadeia de valor e a integração dos recursos de todos os evolvidos em um mecanismo sistêmico.

O processo e convergência assumem uma postura proativa, focada em resultados coletivos, pois se criar oportunidades é uma das principais habilidades da pequena empresa (PEREIRA e GONÇALVES, 1995), desenvolvê-las de forma competitiva, diferenciada e sustentável é uma competência que a gestão de design, incrementa e potencializa com maestria, "pois manter uma vantagem competitiva requer um compromisso contínuo com a inovação" (HIL e JONES, 2013, p. 161). 
Portanto a garantia da qualidade, da responsabilidade social e da gestão ambiental passam a ocupar uma função de destaque na estrutura organizacional (VALLE, 2006), pois a qualidade ambiental passa a incorporar o valor patrimonial da marca.

O bem-estar social geral (PEARCE et al, 1994) está na pauta das discussões e este posicionamento nos remete ao princípio da ética ecocêntrica (WEARING e NEIL, 2001) num comportamento proativo desenvolvido através da vivência permanente da contradição entre responsabilidade ambiental e lucro, onde a responsabilidade ambiental é assumida e integrada à missão da empresa, transformando o que outrora era visto como problema, como uma nova oportunidade de negócios (DORNELAS, 2008).

A avaliação dos efeitos ambientais decorrentes de processos e métodos representa um dos pontos mais importantes dentro do modelo de gestão ambiental e a proteção do meio ambiente, exige a adaptação e transformação de técnicas e processos. Requer um banimento de um ambientalismo superficial (CARVALHO JÚNIOR, 2004).

Assim a transformação de técnicas e processos industriais acontece diante de inovações e a aplicação dessas tecnologias implica diretamente em consequências positivas, entre as quais pode-se destacar a integração do processo produtivo em um ciclo que também inclua as alternativas para destruição dos resíduos e a maximização futura do seu reaproveitamento (SCHENINI, 1999).

A abordagem da cocriação por meio da gestão de design pode intermediar estas técnicas e ou ainda ampliar ou criar novos mecanismos que diminuam o passivo ambiental, tornando as empresas rurais e pesqueiras mais sustentáveis, sobretudo diminuindo os passivos ocultos, desenvolvidos "por atos de negligência ou por ações involuntárias" (PEREIRA, et al, 2002, p. 5).

Na visão de Cerqueira (1994), o mundo está passando por uma fase de mudanças muito rápidas. Essas oscilações são apenas parte da rápida evolução social, tecnológica que a humanidade vem experimentando. Por estas razões a gestão de design pode contribuir, através de um diagnóstico estratégico, para a promoção de valor como elemento diferenciador nas plantas organizacionais (MOZOTA, 2011).

Neste sentido a gestão de design por sua capacidade de entrelaçar-se em todos os níveis da planta, contribui para o aumento dos níveis de responsabilidade socioambiental nas pequenas empresas rurais e pesqueiras, melhorando a percepção dos clientes.

Com este panorama contextual, Prahalad e Ramaswamy (2004), propuseram um modelo de atividade econômica numa relação consumidor empresa consumidor, em que o papel do cliente passa a ter relevância na criação de valor e isso permite gerar novas oportunidades. Las Casas (2008) aponta que esta interação ajuda na criatividade, como boa fonte de ideias e essa abordagem produz vantagens para as pequenas propriedades rurais e pesqueiras, como pode ser observado no Quadro 2.

Quadro 2: Vantagens da abordagem da cocriação em empresas rurais e pesqueiras.

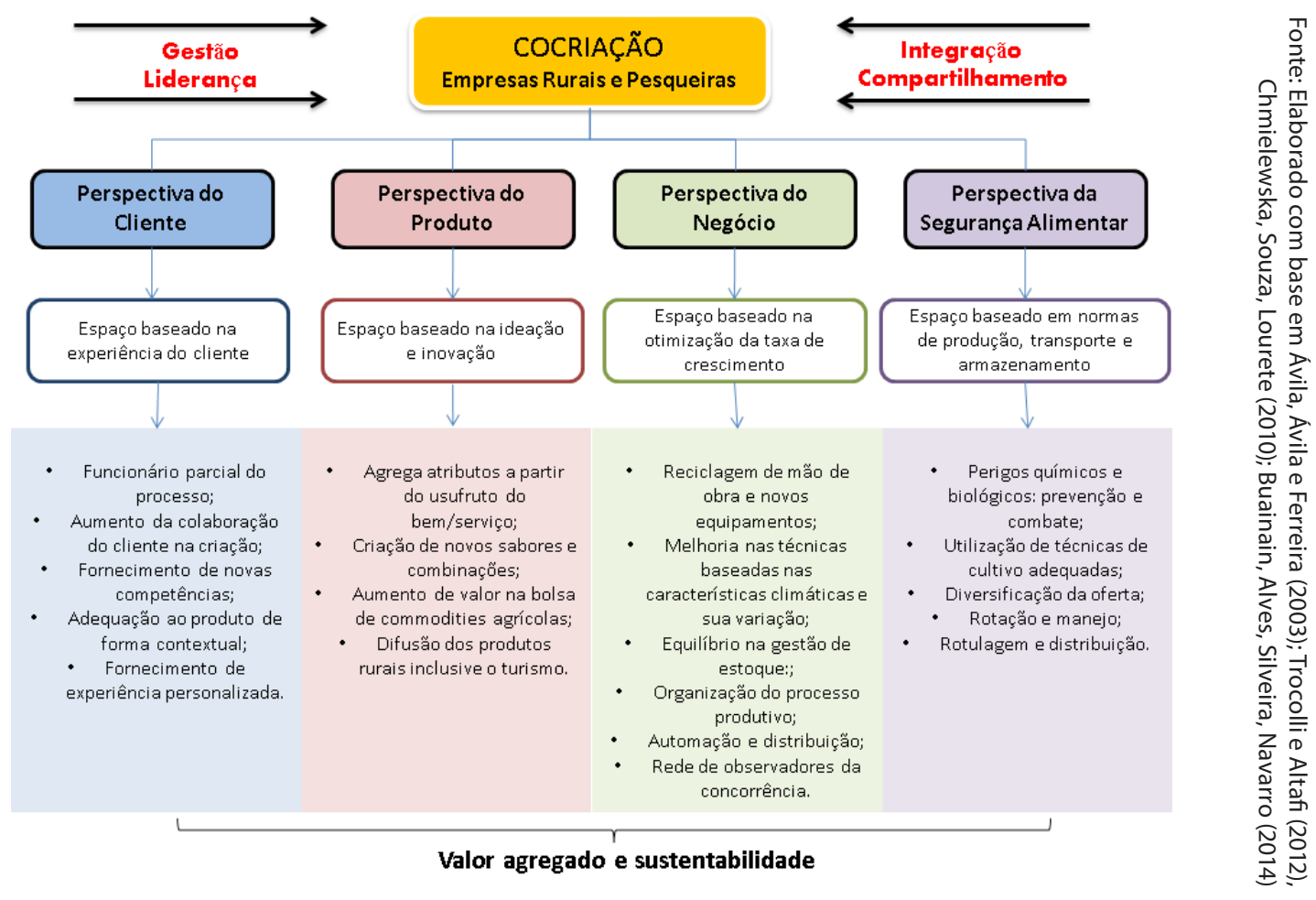


A experiência do cliente, da ideação e inovação, da otimização da taxa de crescimento e da aplicação de normas de produção, transporte e armazenamento são algumas das maneiras das empresas rurais se beneficiarem com a abordagem da cocriação.

O desempenho das atividades produtivas deve levar em conta a oscilação dos preços, imprevistos fitossanitários, climáticos; a sazonalidade da produção, a interferência dos governos, as manobras da agroindústria patronal e a identidade do produto, forma e rotulagem. A abordagem da cocriação oferece subsídios para que a tomada de decisão seja menos traumática e os custos de produção não engulam os resultados globais na balança, desequilibrando as relações entre oferta e demanda.

Em seus estudos, Costa (2013) apresenta três modelos teóricos de cocriação e aponta que o tema vem ganhando espaço no mercado. O primeiro modelo é o de Prahalad e Ramaswamy (2004), chamado de blocos de interação, conhecido como DART. Neste modelo a empresa abre um canal de comunicação; estabelece acesso à experiência e a informação; avalia os riscos benefícios uma vez que a empresa e o cliente assumem e calculam os riscos; e promove transparência, que estimula uma relação de confiança.

O resultado do bloco de interação construído por meio do acrônimo DART, é um estreitamento e um profundo engajamento dos clientes, vez que o Diálogo cria e mantém interações contínuas. Este vínculo é construído por meio do Acesso a informação necessária que cliente recebe e a organização oferece com Transparência, mediante o compartilhamento dos Riscos advindos dessa cocriação.

Especificamente para o caso em tela, a criação de um canal de comunicação em pequenas propriedades rurais e pesqueiras facilita o relacionamento de indicativos para que a tomada de decisão seja mais equilibrada nas dimensões econômica, ecológica e social. Contudo a ideia de um compartilhamento do risco é mínima uma vez que a tomada de decisão final ainda é unilateral e até agora esta nas mãos do produtor.

O segundo modelo é apontado como o de encontros, desenvolvido por Payne; Storbacka; Frow (2008). Os processos são realizados pela empresa e pelos clientes através de pontos de contato previamente estabelecidos. Baseiam-se em processo de cocriação de valor do cliente, processo de cocriação de valor da empresa e processos de encontro.

Finalmente o último modelo apontado é o de interação de recursos, elaborado por Arnould, Price e Malshe (2006), numa tentativa de focar os recursos necessários e interagir com os da empresa.
Por ocupar-se de recursos físicos, humanos e materiais, da comunicação e do ambiente, a gestão de design cria oportunidades estratégicas e Teixeira (2011) estimulado em fundamentar os benefícios que a gestão de design pode oferecer com sua prática e escopo estratégico, traz para o diálogo Castelão e Landim (2009) que afirmam que gestão de design é uma ferramenta estratégica dado que integra áreas distintas da empresa afetando na imagem do sistema.

Portanto a gestão de design, com o uso da abordagem da cocriação, incrementa os pressupostos da gestão ambiental e possibilita, fornece e assegura a "materialização de uma ideia que propõe um processo de transformação na sociedade" (MARTINS; MERINO, 2011, p. 71).

Dessa forma à medida que a gestão de design vai incorporando-se como plano geral de ação principal no seio das organizações, a condução das questões estratégicas voltadas para o desenvolvimento de práticas menos agressivas ao meio ambiente vão se avolumando em forma e estrutura, e isso, proporciona equilíbrio nas tomadas de decisão.

A perspectiva da cocriação finalmente proporciona em suma o desenvolvimento agrícola e agrário. A primeira como "referindo exclusivamente às condições da produção agrícola e/ou agropecuária, suas características, no sentido estritamente produtivo" e a segunda com o "mundo rural em suas relações com a sociedade maior, em todas as suas dimensões, e não apenas à estrutura agrícola, ao longo de um dado período de tempo" (NAVARRO, 2001, p. 86).

A gestão de design por meio da cocriação assume papel de protagonismo nas relações com o mercado e incorpora nas pequenas empresas rurais e pesqueiras, além dos aspectos estéticos e simbólicos, emocionais e de valor, elementos que entronizam a percepção do bem estar físico e emocional. Isso permite a promoção do conceito de saúde individual e coletiva como resultado das complexas inter-relações entre os processos biológicos, ecológicos, culturais e socioeconômicos que se materializam em uma sociedade (OPS/OMS, 2016).

Neste panorama o conceito de saúde se entrelaça ao desenvolvimento de forças produtivas, pelo tipo de relações sociais estabelecidas, pelo modelo econômico vigente, pelo desenvolvimento e forma como o Estado se organiza e as condições com que a sociedade se relaciona e desenvolve com o seu clima, sua localização, seu solo, características geográficas e recursos naturais disponíveis (OPS/OMS, 2016), o que estimula comportamentos mais equilibrados e saudáveis em todos os níveis relacionais. 


\section{CONCLUSÕES}

Os mecanismos de fortalecimento da agricultura familiar com diferentes instrumentos para uma política nacional exigem das propriedades rurais uma nova lógica de produção.

A desaceleração de economias pujantes e o encurtamento de outras cadeias produtivas, entre elas, aquelas ligadas à agricultura familiar, requer eficiência tecnológica e gerencial, além das exigências de processos produtivos menos agressivos no que concernem as questões econômicas, ecológicas e sociais.

Neste sentido os estudos da cocriação como abordagem de convergência por meio da gestão de design nos fazem crer, a partir das pesquisas realizadas para este artigo, que a aproximação do conceito em pequenas propriedades requer mais embasamento uma vez que os modelos teóricos ainda são relativamente novos, sobretudo no que diz respeito ao compartilhamento dos riscos, visto que até o presente momento a tomada de decisão ainda está nas mãos das empresas.

Portanto conclui-se que o presente estudo é parte desse pequeno universo e que novas movimentações teóricas e metodológicas devem ser estimuladas, com a finalidade de ampliar este escopo teórico para que a abordagem da cocriação mediada pela prática da gestão de design contribua para o desenvolvimento sustentável na práxis produtiva e gerencial das pequenas propriedades rurais e pesqueiras.

Portanto destaca-se que este estudo não é, e nem pretende ser conclusivo no que se refere a tentativa de supor que o desenvolvimento sustentável pode também ser estimulado pela abordagem da cocriação por meio da gestão de design.

Uma pesquisa mais detalhada, com a abertura de um canal de comunicação entre os clientes e mais de um produtor rural, aplicando um ou mais modelos apresentados neste artigo, por exemplo, é recomendável, uma vez que possibilitará o alargamento do tema para que avaliações comparativas possam ser efetuadas e hipóteses levantadas, confirmadas ou não.

No entanto, parece claro que os desafios para enfrentar e resolver questões ambientais nas pequenas empresas rurais e pesqueiras, por meio da gestão de design, e da abordagem da cocriação, estabelece parâmetros muito mais claros.

Esses mesmos parâmetros aumentam ainda mais os níveis de diferenciação e posicionamento da oferta de produtos e serviços, pela consistência e nível de confiança construído a partir da abertura de um canal para diálogo e decisão do que se fazer em relação à preservação do planeta e da saúde do homem.

\section{REFERÊNCIAS}

ARNOULD, E. J.; PRICE, L.; MALSHE, A. Toward a cultural resource based theory of the customer in the service dominant logic of marketing: dialog, debate, and directions. New York: ME Sharp, p. 91-104, 2006.

ASSINATURA VISUAL CIRCO DE SOLEIL. Disponível em https://en.wikipedia.org/wiki/Cirque_du_Soleil. Acesso em 03 de novembro de 2016.

ADMINISTRADORES.COM. Co-criação como modelo de engajamento do cliente: fiat e nike mostram cases criados com informações do consumidor. Disponível em http://www.administradores.com.br/. Acesso em 03 de novembro de 2016.

AUSTIN, James E.; REAVIS, Cate. Starbucks e conservation international. Havard Business School. setembro de 2002.

BRASIL. Ministério do Desenvolvimento Agrário. Plano safra da agricultura familiar: alimentos saudáveis para o campo e a cidade. Brasília: Ministério do Desenvolvimento Agrário, 2016.

BRASIL. Ministério do Desenvolvimento Agrário. Dados internacionais. Brasília: Ministério do Desenvolvimento Agrário. Disponível em http://www.agricultura.gov.br/internacional. Acesso em 01/ novembro de 2016a.

BARROS, Jose Roberto Mendonca de. A agropecuária brasileira é um sucesso: prolegômenos. In.: BUAINAIN Antônio Márcio; ALVES, Eliseu; ZANDER, SILVEIRA, José Maria da; NAVARRO, Zander. O mundo rural no Brasil do século 21: a formação de um novo padrão agrário e agrícola. Brasília: Embrapa, 2014.

BARBARÁ, Saulo. Gestão por processos: fundamentos, técnicas e modelos de implementação: foco no sistema de gestão de qualidade com base na ISO 9000:2000. Rio de Janeiro: Qualitymark, 2006.

BANDEIRA, Anselmo Alves. Avaliação de desempenho: uma abordagem estratégica em busca da proatividade. Rio de Janeiro: Qualitymark, 2007.

BUAINAIN, Antônio Márcio, ALVES, Elizeu; SILVEIRA José Maria da; NAVARRO, Zander. O mundo rural no Brasil do Século XXI: a formação de um novo padrão agrário e agrícola. Brasília: EMBRAPA, 2014. 
CONCEIÇÃO, Júnia Cristina P. R. da. Política de comercialização agrícola no Brasil. In.: GRISA, Cátia; SCHNEIDER, Sérgio. Políticas públicas de desenvolvimento rural no Brasil. Porto Alegre: Editora da UFRGS, 2015.

CHMIELEWSKA, Danuta; SOUZA, Darana; LOURETE, Acácio Alvarenga. $O$ programa de aquisição de alimentos da agricultura familiar (PAA) e as práticas dos agricultores participantes orientadas ao mercado: estudo de caso no Estado de Sergipe. IPEA. Instituto de Pesquisa Econômica e Aplicada. Brasília: IPEA, 2010.

CARVALHO JÙNIOR, Antônio Ferreira de. Ambientalismo superficial ou ecologia profunda? São Paulo: Arte e Ciência, 2004.

CERQUEIRA, J. P. de. ISO 9000, no ambiente da qualidade total. Rio de Janeiro: Imagem, 1994.

COSTA, Daniel Ferreira da. Co-criação: uma perspectiva do consumidor. Dissertação de mestrado. Faculdade de Administração e Contabilidade de Ribeirão Preto: USP: Ribeirão Preto, 2013, 162 p.

CASTEIÃO, A L. \& LANDIM, P. C. Quatro modelos de Gestão Organizacional comprovando a qualidade por meio do Design. Bauru: Congresso Internacional de Pesquisa em Design - CIPED, 2009.

DELONG, Thomas J.; VIJAYARAGHAVAN, Vineeta. Cirque du solei. Havard Business School. Abril de 2006.

DAFT, Richard L. Administração. São Paulo: Thomson Learning, 2005.

DAVILA, Tony; EPSTEIN, Marc J.; SHELTON, Robert. As regras da inovação. Porto Alegre: Bookman, 2007.

DORNELAS, Empreendedorismo. Rio de Janeiro: Elsevier, 2008.

DELL. JORNAL DO COMÉRCIO. Cocriação envolve clientes e empresa. Jornal do comércio, 30 de julho de 2010: Porto Alegre. Disponível em http://jcrs.uol.com.br/. Acesso em 03 de novembro de 2016.

FAO. Food and agriculture Organization of the United Nations. Towards stronger: family farms: voices in the international year of family farming. FAO: Rome, 2014.
FIGUEIREDO, Luiz Fernando Gonçalves de; MERINO, Eugenio; MUNIZ, Marco Ogê; MERINO, Giselle. Aplicação do design em casos de Inovação social do Estado de Santa Catarina, Brasil. In.: $5^{\circ}$ Congresso Brasileiro de Pesquisa e Desenvolvimento em Design. Gramado - RS. P. 2-12, 2014.

FERGUSON, Marilyn. A conspiração aquariana. São Paulo: Record, 1991.

FERRARI, Dilvan Luiz, et al. Agroindústrias familiares: estratégias e desafios da inserção mercantil em Santa Catarina. In.: ESTEVAN, Dimas de Oliveira, MIOR, Luiz Carlos. Inovações na agricultura familiar: as cooperativas descentralizadas em Santa Catarina. Florianópolis: Insular, 2014.

GARCIA, Lucas José. A importância do design na viabilização de embalagens para uma micro e pequena empresa da maricultura. In.: $11^{\circ}$ Congresso Internacional de Pesquisa em Design. Bauru - SP. P. 15101516, 2009.

GRILLO, Tito Luciano Hermes et al. Analysis of effect of customer citizenshio behavior on repurchase intention. In.: Revista de Ciências da Administração. v.16, n.40, p. 156-172, dez, 2014.

HIL, Charles W.L. e JONES, Garet. 0 essencial da administração estratégica. São Paulo: Saraiva, 2013.

IPEA. Instituto de Pesquisa Econômica Aplicada. Turbulência global não tem prazo para terminar. In.: Revista de Informações e Debates. Ano 13, edição 87, 2016. Disponível em http://www.ipea.gov.br/desafios/index.php?option=com_content $\&$ view $=$ article $\& i d=3278 \&$ ltemid=8. Acesso em 01 de novembro de 2016.

KOTLER, Philip. Administração de marketing: análise, planejamento, implementação e controle. São Paulo: Atlas, 1998.

LAS CASAS, Alexandre Luzzi. Qualidade total em serviços: conceitos, exercícios e casos práticos. São Paulo: Atlas, 2008.

MERINO, Giselle Schmidt Alves Díaz. A contribuição da gestão de design em grupos produtivos de pequeno porte no setor da maricultura: o caso AMPROSUL. 2010. 146f. Dissertação (Mestrado em Design Gráfico) 
- Programa de Pós-Graduação em Design e Expressão Gráfica, UFSC, Florianópolis, 2010.

MATOS, S.; et al. Inserção do design em micro e pequenas empresas: elaboração de um mapa estratégico. Revista Estudos em Design, № 2, Vol. 22, 2014. [S. n P.]. Disponível em http://www.eed.emnuvens.com.br/ design/issue/view/16. Acesso em 22 de set. de 2015.

MUNIZ, Marco Ogê; SANTOS, Agnaldo dos Santos. A pesquisa em design para o comportamento sustentável: desafios e lacunas. In.: Revista Mix Sustentável. V.1, n.1 - p. [?], 2015.

MONTIBELLER FILHO, Gilberto. O mito do desenvolvimento sustentável: meio ambiente e custos sociais no moderno sistema produtor de mercadorias. Florianópolis: Editora da UFSC, 2004.

MALAGUTI, Cyntia. Design e valores: materializando uma nova cultura. In: ENSUS, 2008. II Encontro de sustentabilidade em projeto. Vale do Itajaí. 9, 10 e 11 de abril de 2008.

MERINO, E. Valorização da produção de grupos produtivos de pequeno porte vinculados à sua origem, com base na competitividade, diferenciação e sustentabilidade. Projeto internacional de pesquisa, 2008.

MARQUES, Luciana. 0 processo de implementação do modelo de inteligência competitiva. Conferência Internacional. São Paulo, 2007

MOZOTA, B. B. Gestão do design: usando o design para construir valor na marca e inovação corporativa. Porto Alegre: Bookman, 2011.

MARTINS, R.; MERINO, E. Gestão de design como estratégia organizacional. Londrina: EDUEL, 2011.

MISSER, Sunil A. Stakeholder engagement: creating value and delivering performance, Deutsche Post DHL, 2013. Disponível em http://www.accountability.org/. Acesso em 03 de novembro de 2016.

NETO A.; TEIXEIRA, J. M.; MERINO, E. A contribuição da Gestão de Design na valorização de grupos produtivos de pequeno porte vinculados a origem. In: $5^{\circ}$ CIPED, 2009, Bauru. Congresso internacional de Pesquisa em Design. Bauru: CIPED, 2009. v. 5, p. 960 - 966. CD-ROM.
NAVARRO, Zander. Desenvolvimento rural no Brasil: os limites do passado e os caminhos do futuro. In.: Estudos Avançados. Vol. 15, n. 43, São Paulo. Set./Dez. 2001.

NATURA. Cocriando natura. Disponível em http:// cocriando.natura.net/cs/cocriando/jornadascocriando. Acesso em 03 de novembro de 2016.

OPS/OMT. Planificación local participativa: metodologías para la promoción de la aalud en América Latina y el Caribe. 1999. Disponível em http://isags-unasul.org/ ismoodle/isags/local/pdf/modulo5/planificacion_local_ participativa_metodologias_para-la_promocion_de_la_ salud_en_alc.pdf. Acesso em 23 de outubro de 2016.

OCED/FAO. Perspectivas agrícolas 2015-2024. OECD Publishing, París, 2015.

PRAHALAD, C.K. \& RAMASWAMY, V. The Future of Competition: Harvard Business School Press: Boston, Massachusetts, 2004.

PORTER, M. Competição: estratégias competitivas essenciais. Rio de Janeiro: Campus, 1999.

PINHEIRO, Igor Reszka; MERINO, Eugenio Andrés Díaz. Os 4 vetores da inovação: um quadro de referência para a gestão estratégica do design. Revista Estudos em Design, V. 23, n2, 75-101, 2015.

PEREIRA JÚNIOR, Paulo Jorge C.; GONÇALVES, Paulo Roberto $S$. A empresa enxuta: as ideias e a prática que fazem das pequenas empresas as organizações mais ágeis do mundo. Rio de Janeiro: Campus, 1995.

PEARCE, D.; et al Blueprint for a green economy. London: Earthscan Publication Ltd, 1994.

PEREIRA, Anísio Candido; GIUNTINI, Norberto; BOAVENTURA, Wilson Roberto. A mensuração dos passivos ocultos: um desafio para a contabilidade. In. IX Congresso Brasileiro de Custos - São Paulo, SP, Brasil, 13 a 15 de outubro de 2002. Disponível em http://www.abcustos.org.br/congresso/view?ID_CONGRESSO=13. Acesso em 15 de out. de 2015 .

PRAHALAD, C.K. \& RAMASWAMY, V. The Future of Competition: Harvard Business School Press: Boston, Massachusetts, 2004. 
PAYNE, A. F.; STOORBACKA, K.; FROW, P. Co-creation of value. Journal of the Academic Marketing Sciece. v. 36, p.83-96, 2008.

SABOURIN, Eric; SAMPER, Mário; MASSARDIER, Gilles. Políticas públicas para as agriculturas familiares: existe um modelo latino-americano? In.: GRISA, Cátia; SCHNEIDER, Sérgio. Políticas públicas de desenvolvimento rural no Brasil. Porto Alegre: Editora da UFRGS, 2015.

SEIFERT, Mari Elizabete Bernardini. ISO 14001 sistemas de gestão ambiental: implantação objetiva e econômica. São Paulo: Atlas, 2007.

SEBRAE. O quadro de modelo de negócios: um caminho para criar, recriar e inovar em modelos de negócios. 2015. Disponível em http://www.sebrae.com.br. Acesso em 21 de outubro de 2016.

SEBRAE. 2016. Benefícios da cocriação. Produção SEBRAE. São Paulo/Camila Cambraia. Programa Emprego \& Renda. Associação de Desenvolvimento de Radiodifusão de Minas Gerais. [20?] Video partes. I e II. (15min19seg,): VHS, color. Disponível em www.sebrae.com.br. Acesso em 23 de outubro de 2016 .

SHETH, Jagdish e PARVATIYAR, Atul. The evolution of relationship marketing. Revista Internacional de Negócios. V. 4, no 4, 397-418., 1995.

SCHENINI, Pedro Carlos. Avaliação dos padrões de competitividade à luz do desenvolvimento sustentável: 0 caso da indústria Trombini de papel e embalagens S/A em Santa Catarina. Engenharia de Produção, 1999. (Doutorado), Universidade Federal de Santa Catarina.

TAKADA, Cíntia; BELLOTTI, Márcia. Engajamento com os stakenholders: manual para implementação. TAKAO Diálogos para Sustentabilidade. 2013. Disponível em http://www.takaoconsultoria.com.br/site/. Acesso 03 de novembro de 2016.

TEIXEIRA, Marcelo Geraldo. 0 método da pesquisa-ação adaptada aplicada à articulação entre o artesanato tradicional e o mercado urbano: uma contribuição para o design. Tese (Doutorado em Engenharia Industrial) Universidade Federal da Bahia. Salvador: Escola Politécnica, 2013.
TEIXEIRA, Júlio Monteiro. Identificação e proteção: o design valorizando grupos produtivos de pequeno porte. Dissertação de mestrado. Universidade Federal de Santa Catarina. Florianópolis, 2010, 179 p.

TROCCOLI, Irene Raguenet; ALTAF, Joyce Gonçalves. Aplicação do modelo da cocriação de valor no agronegócio citrícola paulista. In.: Revista de Política Agrícola, Ano XXI - No 4 - Out./Nov./Dez. 2012

VALLE, Cyro Eyer de. Qualidade ambiental: ISO 14.000. São Paulo: Senac, 2006.

WEARING, Stephen, NEIL, John. Ecoturismo: impactos, potencialidades e possibilidades. São Paulo: Manole, 2001.

WEST, Harry; COUTINO, André. Business design: uma abordagem para empresas brasileiras abraçarem a inovação. In.: Havard Business Review. Dezembro, 2012. 